\title{
THE (NON)-EFFECT OF THE KNOWLEDGE ERA ON UNDER-GRADUATE RESEARCH METHODOLOGY CURRICULA IN THE SOCIAL SCIENCES
}

\author{
CLAIRE WAGNER \\ DAVID JF MAREE \\ Department of Psychology \\ University of Pretoria
}

\begin{abstract}
Educational policy reform in South Africa seeks to address the real-life relevance of curricula, and specifically, reformists have turned to proponents of Mode 2 knowledge to inform initiatives for change. This study aimed to explore the extent to which trends in the knowledge production requirements for higher education are reflected in the beliefs held by academics about the way in which they construct under-graduate research courses. It is proposed that the way forward for curriculum construction lies in establishing academic communities of practice where academics share power and are open to the challenges that they face such as negotiating what is accepted as knowledge.
\end{abstract}

\section{OPSOMMING}

Opvoedkundige beleidshervorming in Suid-Afrika poog om die praktiese toepaslikheid van kurrikula aan te spreek en hervormers beroep hul spesifiek op Modus 2-kennis om verandering te bewerkstellig. Hierdie studie ondersoek die mate waarin tendense in die vereistes vir kennisproduksie vir hoër onderwys gereflekteer word in die oortuigings van akademici oor die manier wat hulle voorgraadse navorsingskursusse saamstel. Dit word voorgestel dat kurrikulumontwikkeling binne akademiese gemeenskappe wat praktykgerig is, gesetel word. Hier kan akademici mag deel en uitdagings, soos wat as kennis gereken kan word, aanspreek.

As changing international trends in higher education make their mark on South African policy, tertiary institutions need to adjust the way in which they deliver education to future generations of South Africans. According to Scott (1997, p. 23) "... the knowledge industry is a key sector within the postFordist economy, and higher education systems are a key component of that industry". Post-Fordism (or neo-Fordism as Robins and Webster (1999) prefer calling it because of the continuing similarities with its preceding era ${ }^{1}$ ) is characterised by features of globalisation and concepts such as skills and knowledge, inter-sectoral co-operation, flexibility and so on. Globalisation signifies the increased interaction that is taking place between communities across the world, which is opening channels for debate and the interchange of knowledge. One of the implications of this global interaction is that sets of values common to homogenous groups are being challenged in order to address the plurality of cultural values that occur within the global village. Globalisation is thus intensifying the need to reexamine the link between theory and practice so that the international community can face the challenges of addressing differences in values and the way in which each community perceives knowledge (McNair, 1997).

Yet globalisation has seen economically developing regions such as Africa marginalised from the mainstream of new societies that base their capital on information. As Castells (1998) pointed out, "[g]lobalization proceeds selectively, including and excluding segments of economies and societies in and out of the networks of information, wealth and power, that characterize the new, dominant system" (p. 161). Being in the embryonic stage of joining the global economy, South Africa will need to ensure that it can successfully integrate into this village and not be sidelined in the process. Accompanying the pressure that globalisation is placing on higher education is the international trend to make higher education more accessible to various marginalised communities such as the working class (thus referred to as massification or democratisation). Economic and social demands that workforces need to be more

Requests for copies should be addressed to: C Wagner, Department of Psychology, University of Pretoria, Pretoria, 0001

1 According to Robins and Webster, a working environment of mass production and repetitive actions marked the period of Fordism. This is in stark contrast to the post-Fordist era where workers have to deal with constantly changing problems. educated and trained than in the past implies that knowledge is no longer dominated by 'élite academic cultures' and higher education institutions must look towards an integration of knowledge generated in partnerships with industry and the state (Kraak, 1997).

The opposition to transcendental knowledge claims (universal truths that apply to all people) and the dominance of elitist academic positions on knowledge production have lead to major changes in how higher education programmes are structured and delivered (Kraak, 2000). Lyotard (1984) recognised this trend two decades ago: "Higher education has become increasingly defined by its capacity to create and produce skills indispensable to competition in world markets and the efficient maintenance of internal social cohesion" (p. 48). Yet, universities are losing their monopoly over knowledge and need to reconsider their position vis-à-vis the way they organise the qualifications they offer. This step is necessary to ensure that universities are able to deliver a different type of worker: "[i]nnovation is at the heart of this new system - the ability to continuously reinvent products and add value to existing designs ..." (Kraak, 2000, p. 3). This implies that education systems will be required to produce such individuals, that is, employees who can function in these learning organisations.

Gibbons, Limoges, Nowotny, Schwartzman, Scott and Trow (1994) coined the terms 'Mode 1' and 'Mode 2' knowledge production to distinguish between past and present ways of doing research and the subsequent learning that takes place. Questions that would illuminate the differences between Mode 1 and Mode 2 could be, for example: Who generates information? Where is the information generated? How is the information structured? Who has access to this information? How is the information presented to people? What impact does this information have on society? The answers to these questions are summarised concisely by Kraak (2000) in his comparison between elitist and mass, open higher education institutions. Accordingly, elite systems tend to be disciplinebased, closed in terms of the diversity of the people and structures who participate in them and hierarchical in 
management, while delivery of education takes place via face-toface contact. In contrast, the latter type of institution is more open to different groups of people, encourages partnerships with government, the private sector and other major economic or social role-players, and offers many types of modes of delivery. Most importantly, the organisation of learning is not limited to interaction within a discipline, but occurs across fields and even institutions. This makes knowledge trans-disciplinary as it includes elements from all disciplines into a type of hybridised science that cannot be fitted back into the separate subjects of Mode 1 learning.

This trans-disciplinary and trans-institutional nature of Mode 2 is, according to Gibbons et al. (1994) and Scott (1995), what characterises the new way in which organisations will function. Knowledge is not something held within elite academic circles for the sake of academia, but it is generated within the context of real-world problems that need to be solved in industry. Hence, Kraak (2000) refers to these solutions as 'socially accountable knowledge' because of their meaningful contribution to society or their applications in industry. The solutions are also characterised by heterogeneity in that different processes are used in innovative ways to find answers. The implication of the above discussion is that learners who enter higher education systems should exit as trans-disciplinary problem solvers and innovative knowledge producers.

According to Kraak (2000), the various policies mentioned imply that Mode 2 research is more useful to address the demands of the current world economy and thus should be ranked above Mode 1 research. This position has, however, been questioned by some individuals and a critique is set out below.

\section{Should mode 2 learning and research be afforded a privileged place in higher education?}

The heading of this section asks the important question of whether Mode 2 should supplant Mode 1 education and research in tertiary institutions. Should educators uncritically accept a different way of structuring learning and change curricula by developing programmes that are flexible, transdisciplinary, focused on problem-solving, interdependent, relevant to a specific context, funded from many sources and so on (issues that will be elaborated on below)? In other words, this position accepts that Mode 2 knowledge production has profound implications for the way in which we teach students and the knowledge they will need to compete in a society that demands specific kinds of skills. Another assumption that is made, for example, is that there are vast differences between the current curriculum and the type of syllabus that proponents of Mode 2 would put forward. Muller (2000, p. 50) warned that "[academics] may for convenience simply teach their Mode 2 involvements instead of what the curriculum requires" and that academics will be less involved with students as a result of commitments to their own research agendas. An academic's position as a research consultant to various sectors of society may thus be afforded a privileged place and affect the kind of teaching that they do (Brew, 2003). An advantage of this may be that students will receive more upto-date content in the curriculum and thus be better prepared for the types of positions they will occupy in the real world of work (Muller, 2000).

On a higher level than curriculum design, Robins and Webster (1999) identified a crucial point regarding the future of the university within the context of a post-Fordist society. It is Robins and Webster's contention that the characteristics of this economically driven era (constant change, for example) are defining the learning that is taking place at some universities. Learning programmes are thus being adjusted to suit an economic agenda. Also, universities have been influenced by international trends of societies that hold institutions accountable for how they spend their money. In this environment, business traditions are mimicked in order to generate non-governmental income and the marketisation (or commercialisation) of higher education takes place to avoid the criticism that "universities have not managed to supply appropriate outputs, that graduates have most conspicuously lacked the "transferable personal skills'2 that would make them useful to employers" (Robins \& Webster, 1999, p. 196). In South Africa "governments and employers are calling on education providers to develop generic transferable skills in learners" (Department of Education, 2002). To facilitate this, the Department of Education (DoE) has written generic level descriptors ${ }^{3}$ to describe these skills so that they can be developed and integrated into specific curricula. Mode 2 subscribes to this marketisation agenda as it focuses strongly on partnerships with industry and delivering students with skills that will fulfil industrial needs. Critics of this trend, such as Slaughter and Leslie (1997), have pointed out what they believe the consequence will be of the wholesale adoption of Mode 2: the destruction of traditional academic goals, what Robins and Webster (1999) referred to as 'narratives of decline'. For example, research for its own sake will be replaced by research that can serve the purposes of industry.

An added dimension to this phenomenon is the freedom that post-Fordism affords adherents of post-modernism to advocate the post-modern university. If society is 'flexible', 'constantly changing', 'plural', 'reflexive' and 'diverse' then these traits should be reflected in the institutions of education that serve this society. The Department of Education (2002) has identified this trend by providing generic level descriptors that "can act as a starting point for curriculum planning and quality assurance for providers within and without formal education e.g. for employers offering work-based modules/unit standards". The problem with this approach is aptly illustrated in the citation below:

Thus the university can no longer be identified by virtue of its separation from the outside world, while simultaneously big companies ... are becoming more conscious of their roles as creators, disseminators, and users of knowledge - a definition not altogether different from that of a university (Robins \& Webster, 1999, p. 214).

The question that can consequently be asked is: What right does the university therefore have, above other sectors in society, to be the sole distributor of knowledge? Also, how will the university distinguish itself from other role-players such as industry? These questions are difficult to answer. Although Robins and Webster (1999) made a case for people to remain loyal to the university based on its sentimental ideals of "disinterestedness, critical inquiry, open debate, rigorous examination of evidence ..." (p. 217), this idea seems to be a rather emotional appeal to nostalgia; is it enough to ensure the future of the university in a rapidly changing society?

\section{A more varied approach to categorising research}

Research may, however, be even more varied than suggested by the dichotomous Mode 1 and Mode 2 debate presented above. As Muller (2000, p. 47) stated, "[i]t over-homogenises the evolution of a phenomenon that probably happened much earlier, and it over-dichotomises it, presenting it as two discrete ideal types that probably never exist in their pure form in the real world". The various bodies governing higher education policy in South Africa have recognised the variation in approaches with their categorisation of research into four areas: traditional, applications-driven, strategic and participation-based, but clearly position these areas in Mode 2 learning. The White Paper on Science and Technology: Preparing for the Twenty-First Century published by the Department of Arts, Culture, Science and Technology (DACST, 1996) "explicitly encourages problemsolving research through the formation of societal partnerships and cross-sectoral government policy co-ordination" (Kraak, 2000, 30). Robson (1993) also emphasised that research - or 
enquiry as he terms it - can be viewed as a way of solving problems. The difference, however, between the distinction of Mode 1 and Mode 2 knowledge production and the four areas identified by government on the one hand, and Robson's perspective on the other hand, is that research is placed on a wider continuum. Solving problems ranges from purely theoretical to entirely practical as illustrated in figure 1 . The dimensions also move from pure to applied research and according to increasing contribution from the client. No value judgement is attached to the dimensions; where a particular study lies on the continuum depends on the circumstances of an individual project.

Robson's five dimensions do not adequately represent the characteristics of Mode 2 knowledge production as outlined in the previous section. A sixth dimension has therefore been added, namely the learning organisation. This portrays the type of research that takes place in a real world setting where the answer can be applied to a problem experienced by the organisation or other sectors of society. This is also referred to as a 'networked' mode of knowledge production, diversity within the organisation that "arises because Mode 2 is the outcome of teams of knowledge workers with diverse backgrounds, who in most cases are employed in pursuit of innovation by networking firms" (Kraak, 2000, p. 14). Muller (2000) would not place this type of research within the framework that has been provided above, as he views knowledge production of this kind as positioned outside of pure and applied research conventions. Similar to Kraak's intended meaning cited above, Muller characterises the learning organisation as a place where interaction on a social level provides the necessary route to the kind of Mode 2 research described. To provide a clear picture to the reader of the contrasts and developments in the dimensions of research, however, the addition has been placed in figure 1 .

Higher education and training institutions are thus faced with the challenges of engaging in the debate and positioning themselves in terms of Mode 1 and Mode 2 knowledge production. How these debates have been transformed into concrete measures to address the situation of South African education will be discussed in the following section.

The effects of mode 2 learning on higher education policy and research in South Africa

Notwithstanding the reservations of certain academics and alternative views on the merits of Mode 2 learning, new higher education policies have been implemented (to lesser or greater degrees) in South African tertiary institutions. The South African government has recognised and integrated the trends of globalisation and massification in its policies affecting higher education. Indeed, Kraak (2000) identifies clear signs of Gibbons et al.'s (1994) and Scott's (1995) work in the documents released by government, such as the National Commission on

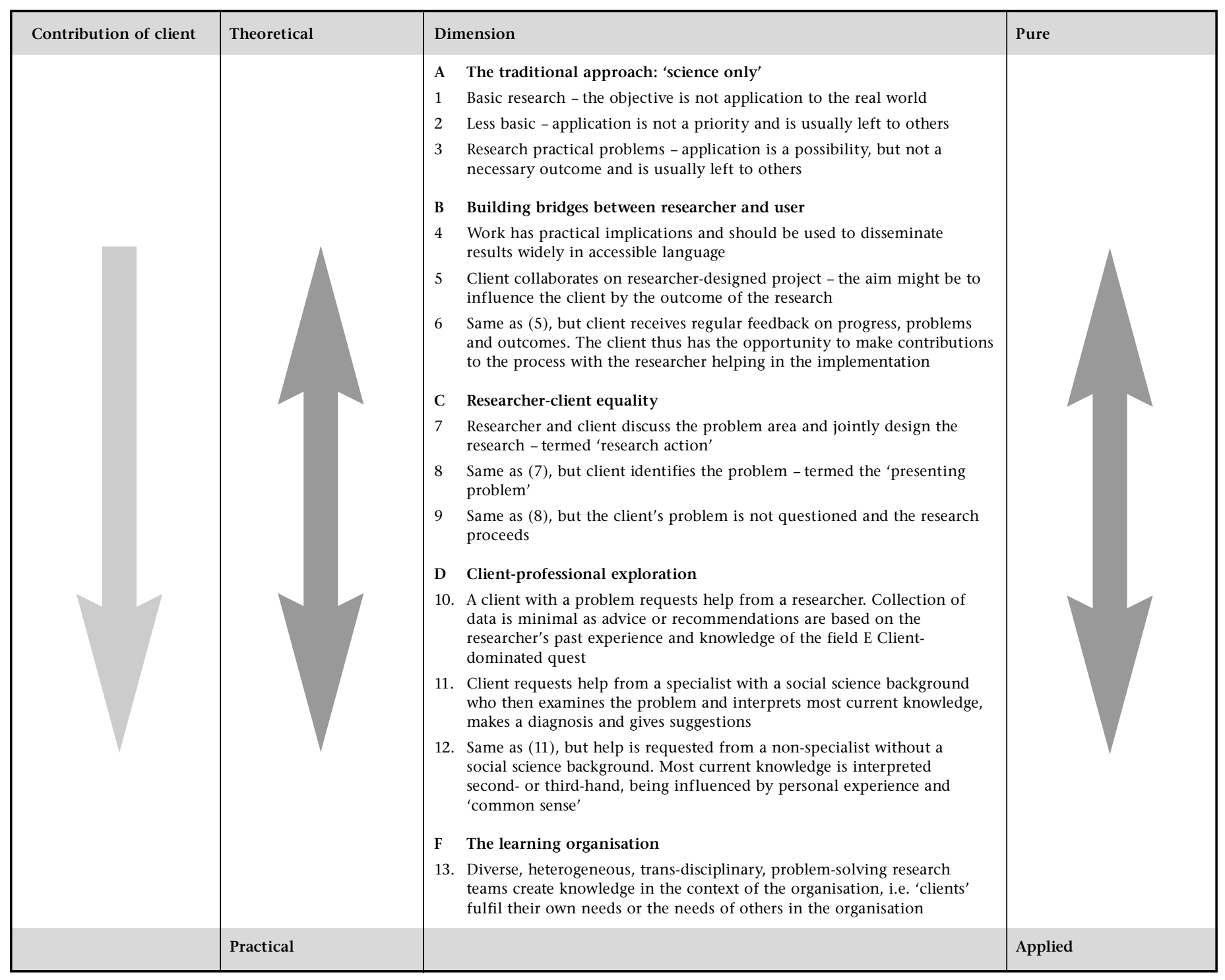

Figure 1 Approaches to solving research problems

(Adapted from Robson, 1993) 
Higher Education's (NCHE) final report, A Framework for Transformation, released in 1996, the DoE's Green Paper on Higher Education Transformation released in 1996, the Education White Paper 3: A Programme for the Transformation of Higher Education, also released by the DoE in 1997, and the 1997 Higher Education Act. Kraak (2000) categorises the NCHE report into five areas of recommendations regarding the transformation of higher education ${ }^{4}$. These recommendations loosely overlap with the characteristics of Mode 2 learning institutions as set out briefly above. The implementation of the new policy in South African higher education would have certain consequences such as massification (by increasing student numbers and an increase in diversity in terms of the type of student and flexibility in the structure of how qualifications are presented), interdependence (by forming new relationships between tertiary institutions and key stakeholders in society), social accountability (by responding more actively to social and economic concerns), centralisation of planning (by putting a National Higher Education Plan in place to ensure a systematic approach to preparing South Africans for suitable roles in the global economy), preservation of institutional identity (by allowing institutions to initially retain their own identities and niche in the education market), providing programmes instead of courses and qualifications (by integrating and transforming isolated courses into broad programmes with a specific focus).

Besides the implications of new policy for higher education described above, an essential aspect of the recommendations for transformation that is relevant to this study deals with the changes that are touted by policy for research practice. The NCHE (1996) accepts the changing dynamic of knowledge creation, which encapsulates the themes of globalisation, massification, trans-disciplinarity and the practical contribution of research to societal problems. The financial support made available for research projects also reflects these changes: "[f]unding is almost always from more than one source requiring different forms of interaction, accountability and management. Knowledge is increasingly trans-disciplinary and trans-institutional (a widened social base participating in its construction) ..." (NCHE, 1996, p. 126). Besides the new types of general skills that students must have to cope in the knowledge economy, under-graduate courses in research methodology should reflect the different way in which research is practiced in this environment. A module in research methodology will thus form part of and needs to fit into a broader programme. Students should be able to demonstrate certain skills on completion of a course that reflect the competencies they have acquired (Robins \& Webster, 1999). More specifically, students should be equipped to secure funding (depending on the context they practice in) for research that is relevant and accountable, that is based on partnerships across various sectors of society and that makes use of different disciplinary fields.

Robins and Webster (1999) argued that this new context is driven by socio-economic imperatives which means that the structure and content of higher education will have to be linked to the requirements set by industry to train workers who will cope in this environment. As noted earlier, many of these features have made an appearance in documents released by government departments tasked with transforming the education sector in South Africa. For example, the NCHE (1996, p. 7) stated that "[h]igher education institutions will increasingly have to offer a greater mix of programmes, including those based on the development of vocationally-based competencies and skills needed in the workplace". In particular, statements have been made about the role that (social science) research should play in achieving the government's goals. The White Paper on Science and Technology released by the Department of Arts, Culture, Science and Technology (DACST, 1996) implies that the social sciences have not been making the kind of contribution that is necessary to effect the transformation in South African society that the government requires and that this should change. Tothill and Crothers (1997) asserted that this situation could be remedied by improving the class of education received by students, as future researchers, in the social sciences.

The assumption that can thus be articulated from the literature discussed above is that the curricula of under-graduate research courses at South African universities need to be re-examined in the light of the changing context of higher education in order to make suggestions about transformative actions that can be taken to improve the status quo, if necessary. One of the aims of this study is to examine how research courses have portrayed the policies of government in their curricula. Furthermore, any signs of the impact of the changing research environment will be sought. One of the ways in which to examine these two aspects is to explore the way in which academics that construct undergraduate research courses talk about the curriculum. The research question that this article considers is thus: How are the trends in Mode 2 requirements for higher education reflected in the beliefs held by academics that inform the way in which they think they should or should not construct under-graduate research courses?

\section{METHOD}

\section{Research design}

In order to explore the beliefs held by academics, a qualitative research design was chosen, as it would allow the researcher to hold in-depth, semi-structured conversations with participants to explore their talk about their curricula. In agreement with Polkinghorne (1983, p. 267), "the face-to-face encounter provides the richest data for the human science researcher seeking to understand human structures of experience", and interviews are seen as the most intuitive way of uncovering meanings in this context. Approaching the people involved in under-graduate research courses provided a first-hand account of how they make sense of the curriculum and the factors that shape, maintain and transform it. Specific individuals were approached with the request to be interviewed about their methodology course(s). Although this study was driven from the discipline of psychology, all the social sciences were included as research methodology is a module that is germane to them. An interview guideline was developed based on the literature that was surveyed about the topic and the results from a larger study (Wagner, 2003) that mapped the content of under-graduate research courses. Semi-structured, in-depth interviews were conducted face-to-face with willing participants. Interviewees who were not in the Gauteng area received a similar interview guideline via e-mail.

\section{Sample}

Much care was taken to include a diverse range of participants in terms of their discipline, the type of course they teach (in terms of the categorisations developed from phase 1 which were: sparse courses (where the number of topics that are covered is small), pluralistic or charismatic (courses that convey many methods in social science research), qualitativebased (based solely on or emphasise topics commonly associated with qualitative research) and quantitative-based (where topics focus on quantitative methods or analysis of quantitative data)), geographical location (linked to the nine provinces in the country), institution in terms of training model (distance, telematic or face-to-face interaction), language of instruction and categorisation in the previous education system.

Out of the 16 potential participants selected (plus a replacement sample of 10 individuals), nine were prepared to be interviewed face-to-face or returned their e-mailed questionnaires. Five females and four males took part in the 
study. The interviewees were typically young or classified themselves as junior staff members; only two people had doctorates at the time of the interviews. The race of the participants was as follows: one black person and eight white people. The interviews were mostly conducted with historically advantaged universities. The mode of interviewing for most of the historically black institutions was e-mail due to their location; very few people from HBUs returned the electronic questionnaire despite the researcher's follow-up requests. Also, very few e-interviews were forthcoming from psychology departments. The researcher purposefully excluded any individuals from her own academic institution as she is intimately involved in all the interdisciplinary research courses presented to under-graduate social science students and therefore preferred to become familiar with courses at other universities. Between the survey of the content of courses and the interviews with some of the lecturers, many of the courses had changed their focus. In most of these cases the course consisted of content dealing with quantitative topics only. This has changed to the majority of courses presenting both quantitative and qualitative methods.

\section{Analysis}

In this section the researcher will explain how the data were analysed using thematic analysis within a critical hermeneutic process of interpretation and meaning reconstruction. Elements of Carspecken's (1996) approach on how to analyse data from a critical hermeneutic epistemology were adapted and applied to the interview material collected. There are a number of reasons for choosing the method described below. The method fits into critical hermeneutic research and is clearly defined by a selfproclaimed critical researcher, Carspecken (1996). Most qualitative (if not some quantitative) researchers will be familiar with the method of thematic analysis. By including coding as a complementary technique to thematic analysis, the researcher was able to distinguish patterns "where we identify a 'type' of occurrence by virtue of it being perceived as an underlying 'common form' found in different contexts" (Kelly, 1999, p. 412). Familiarity with thematic analysis renders it easily understood by others and the explicit explanation of its application below means that it does not result in unnecessary confusion about how the researcher conducted the analysis. Also, this method provided a clear structure for the researcher to work with and allowed for validity checks later on in the analysis as well as peer debriefing.

Once researchers have recorded each respondent's interview in a word processing file coding the data set can begin. Not only is coding necessary for researchers to become aware of patterns in the data and group them together, but uncommon or unique features of the data can also become apparent. This in turn enables the researcher to choose suitable parts of the data for meaning reconstruction (fleshing out and explicitly stating what is said by respondents). The way in which the researcher performed meaning reconstruction in this study was by putting into words - on a low level of inference, that is, remaining close to the interview data - the meaning of what interviewees were conveying to the interviewer about their research course.

The coding method consisted of seven steps adapted from Carspecken's (1996) suggestions for coding. This process begins when researchers open the first word processing file containing the data that they want to code. In step two the researcher opened a new blank file on the screen. Step three consisted of reading through the data in each file that contained data. If the researcher noted something important enough in a file to code, the section was copied and pasted into the blank file and given a code. The researcher tried to keep statements that held similar meanings within and between files together for later convenience. In the fourth step the researcher continued to read through the interviews and noted any differences within an established code, giving sub-codes to opposing or distinct statements. A hierarchical structure of codes was generated in this way. In step five the researcher completed the coding by reading through all the interviews and generating all possible codes or adding to existing codes.

Once the codes were established analytical emphases were chosen on which to base the meaning reconstruction. Carspecken (1996) noted that many criteria could serve to place emphasis on certain aspects of the codes, but that the validity of the emphasis should be foremost in the researcher's mind. The coding structure

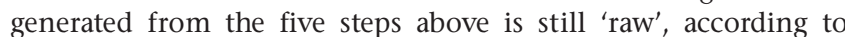
Carspecken (1996), because no organisation of the codes has taken place. Redundancies and intersections between codes still exist and researchers need to pull these codes together. This forms the sixth step of the data analysis where researchers group certain codes and sub-codes together in categories. To facilitate the researcher's task of keeping an uncomplicated appearance in the presentation of the findings, those codes that formed part of a category were renumbered so that they followed a sequence from [01] to [..] across the categories. For example codes [01] to [03] were placed in the first belief category 'Under-graduate curricula should be developed by means of consensus', codes [04] to [05] were placed in the second belief category 'Under-graduate research methodology curricula should be constructed based on the expertise and research experience of academics' and so on. The eventual categories that the researcher formed from the interview data were based partly on suppositions made by the researcher from the findings in part one of the study, the focus of the study and discussions with her supervisor (as a form of peer debriefing). Nonetheless the researcher attempted to remain as close to the data as possible at all times.

The final part of the analysis, step seven, is to name and then flesh out each category to again ensure that the codes for the category fit the statements made by respondents or that a category is robust enough to stand on its own. The criteria that the researcher used to establish a belief category were derived from the codes that were merged in a category. The criteria may reflect alternative points of view amongst respondents. Some overlap between responses in categories does occur where a response refers to two or more beliefs and therefore needs to be placed in two of the categories; not all categories are therefore mutually exclusive.

Within the coding steps described above there are a further five steps that form the hermeneutic circle of interpretation. Due to space limitations the steps in this process are only listed as: virtual intersubjectivity, meaning-making through familiarity with the culture of the actors, reflecting on and identifying the researcher's norms, the normative circle and personal characteristics of research participants versus typical cultural behaviour. Detailed explanations of each of these steps can be found in Carspecken (1996).

The validity of the researchers' initial interpretation (thematic analysis) can be ascertained by assessing whether the participants agree with the statements that have been made (Carspecken, 1996). This is known as member checks where, at any stage of the analysis, the researcher engages with the participants about the process and includes the participants' views of the researcher's interpretation in the final analysis (Richardson, 1996). To perform a member check for the interpretation of the data in this study the themes that emerged from the interviews were sent to the participants and they were requested to send comments. This is a limited adaptation of member validation as the researcher did not engage in sustained dialogues with respondents, but it adheres to Gadamer's (1989) version of hermeneutics of alternating between an unfamiliar scheme and that of our own world. This may lead to the revision of our ideas and the eventual fusion of horizons. Although researchers make their own interpretation of data this is one way of remaining open to improving one's reading of the phenomenon. 


\section{RESULTS}

Three of the nine beliefs held by the respondents concerning the construction of under-graduate research methodology curricula, which relate to the focus of this article, are presented here. The categories are called beliefs because they hold the viewpoints of respondents on how and why the curriculum of their courses came into being.

\section{Under-graduate research methodology courses should} provide students with only a basic introduction to research versus students acquiring research skills

Many of the respondents made it clear that the under-graduate course they teach is only aimed at providing an introduction to research. Students learn useful background knowledge about research that can sometimes be implemented as skills in everyday life situations such as learning from your immediate environment by observing in it, knowing how to introduce yourself when entering situations and critical thinking skills. Some courses intentionally incorporate critical thinking and problem-solving skills in the curriculum, but according to the majority of respondents the courses do not claim to do more than impart knowledge. A few courses have specific outcomes in terms of skills such as enabling students to write a research proposal by the end of the course. The structure of the course is aimed at achieving this. For example "theory is not taught for the sake of it and all unnecessary technical methodological details have been thrown out"

Under-graduate research methodology courses should prepare students for post-graduate research requirements This belief is related to the supervision process of postgraduate students by constructors of under-graduate research courses. Two opposing beliefs were prevalent amongst the interviewees. The first belief is that knowledge of research is not meaningful for the contexts in which a discipline is practised; under-graduate research methodology is only useful to students who continue with post-graduate studies as it forms a basis for the research that students must conduct to attain a post-graduate qualification. Research skills are not seen as fundamental to the discipline, but rather something that can be contracted out to experts such as marketing research companies once the student has become part of a workplace. In one case the under-graduate curriculum was developed to focus only on quantitative research so that the post-graduate curriculum can deal with only the qualitative aspects that students use to complete their studies. These dissertations use mainly qualitative methods because it is believed that, in relation to quantitative methods, they more closely mirror the rest of the training that students receive in the substantive discipline. The second belief is that all professional persons do some degree of research in the execution of their duties, and thus skills in this field are necessary and integral to success in the workplace. For supervisors to forge and maintain relationships with industry, post-graduate dissertation topics should focus on the problems faced by industry and find solutions. Also, research methodology is seen as a skill that can provide students with extra tools to be able to perform at the level expected from them in the workplace.

What these two viewpoints seemed to have in common, however, is that the curriculum has been adjusted from a narrow focus to a broader one so that students receive training in the entire research process in order to feel comfortable when doing research on a post-graduate level. Academics thus believe that they should focus their attention on the needs and requirements of post-graduate qualifications to determine the content of the under-graduate curriculum.

Under-graduate research methodology courses should comply with the current educational framework

Some respondents believe that the current educational policy in South Africa should be taken seriously. The policy has impacted on the development of the research modules in that the new documentation was studied and principles of outcomes-based education were investigated so that academic programmes could be re-designed to build these principles into the courses. In the process most semester subjects were changed into modules. Two approaches were followed within the new dispensation: lecturers either integrated research components into specific modules or they designed research modules on their own. In some cases research methodology became a core module in certain programmes: "The course was designed in this way to allow students to have some knowledge even if they had to leave the programme and find employment in any field of research such as field workers, community facilitators etcetera." Research modules were also rewritten to comply with policy.

Research methodology modules have also been reduced, in some cases, due to outcomes-based education and limited resources in terms of personnel. Structuring a programme according to $\mathrm{OBE}^{5}$ principles results in a proliferation of new modules and, as departments want to include the core modules of a substantive discipline in programmes, research modules are cut. The reduction in space allocated for research has been managed in two ways. Firstly, as mentioned, research has been made an integral part of each module in a substantive discipline. In other words, research methodology does not stand on its own as a module, but forms part of the processes involved in community projects and the like. The second way of managing this problem is by reducing the content of research modules to 'essential' aspects, for example, concentrating on only quantitative methods.

Complying with national educational policy is viewed as a top-down approach where academics do not have much choice. A process is set in motion whereby senior members of staff attend meetings (the aim of the meetings is not always clear) and junior staff have to carry out any decisions made. This can lead to feelings of resentment. As one respondent puts it: "I think amongst academics there's a certain sense of 'we can function independently, we want to make our own decisions' so I think academics are a bit unhappy about this, the top-down thing happening, but it's always been like that but it seems to be more - how can I put it - enforced on another level almost". A tension exists between being an independent academic and having to comply with the national education framework.

Although external forces influence the structure of courses, some academics view academia as allowing them a lot of freedom in terms of benefits such as the amount of vacation time, funding for involvement in departmental projects and attendance of international conferences. Nonetheless, the university as an institution is becoming more bureaucratic due to the increase in administrative duties that academic staff are experiencing, such as exercising more control over mark systems, attending many meetings and serving on committees. This creates a tension between the administrative and academic sides of curriculum development and teaching. One respondent believes that this situation originates with the top management of the institution and could also lie in the need to ease the workload of administrative staff.

\section{DISCUSSION AND RECOMMENDATIONS}

According to Tashakkori and Teddlie (2003), researchers in practice demand 'research experts' that are capable in using both qualitative and quantitative methods. The implication of this for higher education is that "those who teach research methodology in the social and behavioural sciences have a responsibility to prepare their students for a professional world that is increasingly using mixed methods" (Tashakkori \& 
Teddlie, 2003, p. 61). This implies a scientist-practitioner model. It would appear that under-graduate social science students in South Africa are slightly better prepared for practice than their American counterparts, but that the motive for teaching mainly mixed methods courses can be questioned. The contention that providing a mixed methods research course prepares students for current practice and Lyotard's (1984) idea of performativity ${ }^{6}$ do not manifest in the viewpoints of the lecturers. Many interviewees stated that the under-graduate curriculum prepares the student for postgraduate research either through projects that the teachers are involved in or just to serve the achievement of a post-graduate qualification. The academics that were interviewed thus represent under-graduate students as future post-graduates. One implication of this could be that students should be proficient in quantitative and qualitative research so that they can address any academic question that arises. It thus seems that the pressures that academics face drives curriculum content: "[ $\mathrm{t}]$ he production of scientific proof costs money, with the result that scientists who can maximize output (proof) while minimizing input expended in the process of proof (energy, and thus cost) get funded" (Lyotard, 1984, p. 21) and/or promoted and/or respected professionally. It is the current authors' assertion that we are training under-graduate students for their possible future roles as post-graduates for the mileage that we can extract from them in terms of research outputs. Constructors of research methodology courses may thus be strategically structuring the under-graduate curriculum to suit their vested interests, that is, their own academic goals. This is based on their unquestioning beliefs that they are the sole stakeholder in determining how the knowledge that students gain should be constructed.

As academics believe that under-graduates should be educated so that they will be successful post-graduates, their courses are constructed to address this belief and they train under-graduate students to become scientists for the practice of further science rather than becoming scientist-practitioners. Respondents described their courses as 'basic' and 'introductory' and it could be argued on this basis that as researchers ourselves we do not believe that students can be taught to progress beyond this level at an under-graduate stage. The focus of this study is on undergraduate courses as the vast majority of students exit tertiary education with a first degree and depend on this qualification to find work. As social scientists they will be expected to have a certain amount of competency in researching human behaviour and thus, to echo Tashakkori and Teddlie (2003), it is important to prepare them for the contribution that the economy will demand of them.

One interviewee did acknowledge the needs of the workplace in informing curriculum content:

"The feedback that I get is very positive, for example people in government say they have to regularly conduct small projects at work and it [the research course] gave them a lot of guidance." [authors' translation]

It could thus be concluded that although it is strongly embedded in South African higher education policy, the Mode 2 knowledge paradigm discussed earlier is still not considered in under-graduate research curricula. The pressure from both the real world (research practitioners and business) and from government (in their policy and as an employer) to provide people who can answer key research questions is being ignored. Although some influence of the Mode 2 paradigm is evident in the way methods courses are being integrated into the content of substantive disciplines and interdisciplinary cooperation between departments, these activities are limited. Perhaps this reflects a tension between the acceptance and implementation of the Mode 2 paradigm in academic curricula versus more traditional Mode 1 knowledge production practices.
When research methodology is constructed and presented as an integrated course across disciplines in a faculty, positive spin-offs such as the sharing of resources and diversity of training takes place. From the interviews with lecturers, some of the negative consequences of adopting a Mode 2 approach are also evident. One respondent reported that the voices of smaller or non-co-operative departments are silenced. Departments that might make a meaningful contribution to a research course because of their particular field of expertise (Polkinghorne, 1992) are excluded because they have less power in the faculty and course construction is left to larger departments such as psychology and sociology. The way that marginalised departments deal with this situation is by creating 'organisational niches' whereby they "bureaucratise knowledge by subject matter and stake a claim to research and train students in it" (Chubin, 1986, p. 4). In this way a department may see a certain research method as integral to their discipline and claim that they alone are experts on the topic and have the sole right to present related material. This may cause more conflict between disciplines and further marginalisation of small departments.

The suggestions that are made below arise from imperatives in the literature on higher education and research methodology teaching to revise our practices as academics in the way that we construct our curricula. Central to this is the belief that the kind of knowledge and the way in which we teach it needs to be legitimated in a broader arena and not only amongst ourselves (Barnett, 1997; McNair, 1997). A new model for achieving this purpose is proposed by Brew (2003, p. 12) who remarked that

[i]n an academic community of practice, students, academics, professionals and indeed anyone else who shares this site of practice, are responsible for the maintenance of the community of practice for inducting newcomers into it, for carrying on the tradition of the past and carrying the community forward to the future. Persons (students and staff) engage in legitimate peripheral participation in such communities of practice.

This may sound like the type of post-modern university and mode 2 research and teaching model that is described and criticised by Muller (2000) and Robins and Webster (1999). It should rather be viewed as the type of university that Habermas would advocate, where there is open dialogue amongst different parties and the best argument is accepted as the consensus viewpoint: "[ $t$ ]he social norms of such an institution would not be those of mutually hostile isolationism but those of an open, self-reflective and innovative community, whose members share these values" (Blake, 1997, p. 163). Logistically this pathway may seem daunting, as one would need formal structures to ensure that enough time and space is provided for people to air their views. Brew (2003) concurs that this is a great challenge and that higher education has to be radically transformed to achieve this; however, she made some practical suggestions about how one may go about this. For example, graduate students could present some lectures, students could be rewarded by peers for their research work such as publishing articles in a student journal, and electronic formats for debates and conferences between students could be initiated. According to Brew, this also means that academics need to share power and be open to the challenges that they face such as negotiating what is accepted as knowledge and involving students in their research projects. It is thus proposed that the way forward for curriculum construction lies in establishing academic communities of practice that should be viewed as the type of university that Habermas would advocate: where academics need to share power and be open to the challenges that they face such as negotiating what is accepted as knowledge. 


\section{REFERENCES}

Barnett, R. (1997). A knowledge strategy for universities. In R. Barnett and A. Griffin (Eds), The end of knowledge in higher education (pp.166-180). London: Institute of Education.

Blake, N. (1997). Truth, identity and community in the university. In R. Barnett \& A. Griffin (Eds), The end of knowledge in higher education (pp. 151-164). London: Institute of Education.

Brew, A. (2003). Teaching and research: New relationships and their implications for inquiry-based teaching and learning in higher education, Higher Education Research \& Development, 22 (1), 3-18.

Carspecken, P.F. (1996). Critical ethnography in educational research. A theoretical and practical guide. New York. Routledge.

Castells, M. (1998). The information age: Economy, society and culture. Volume 3: End of millennium. Oxford: Blackwell.

Chubin, D.E. (1986). Interdisciplinary analysis and research: Theory and practice of problem-focused research and development. Mount Airy: Lomond.

Department of Arts, Culture, Science and Technology (DACST). (1996). White Paper on science and technology: Preparing for the twenty-first century. Pretoria: Government Printer. Retrieved July 20, 2002, from http://www.gov.za/ whitepaper/1997/sc\&tecwp.htm.

Department of Education (DoE). (2002). Retrieved January 16, 2003, from http://education.pwv.gov.za/DoE_Sites/Higher_ Education/Academic_Policy/chapter\%205.htm.

Gadamer, H.G. (1989). Truth and method (2nd ed.). (J. Weinsheimer \& D.G. Marshall, Trans.). New York: Crossroad. (Original work published 1960)

Gibbons, M., Limoges, C., Nowotny, H., Schwartzman, S., Scott, P. \& Trow, M. (1994). The new production of knowledge: The dynamics of science and research in contemporary societies. California: Sage.

Kelly, K. (1999). Hermeneutics in action: empathy and interpretation in qualitative research. In M. Terre Blanche \& K. Durrheim (Eds), Research in practice: Applied methods for the social sciences (pp. 398-420). Cape Town: University of Cape Town Press.

Kraak, A. (1997). Globalisation, changes in knowledge production, and the transformation of higher education. In N. Cloete, J. Muller, M.W. Makgoba \& D. Ekong (Eds), Knowledge, identity and curriculum transformation in Africa (pp. 51-78). Cape Town: Maskew Miller Longman.

Kraak, A. (2000). Changing modes: A brief overview of the 'Mode 2' knowledge debate and its impact on South African policy formation. In A. Kraak (Ed.), Changing modes. New knowledge production and its implications for higher education in South Africa (pp. 1-37). Pretoria: Human Sciences Research Council.

Lyotard, J.F. (1984). The postmodern condition: A report on knowledge (G. Bennington \& B. Massumi, Trans.). Manchester: Manchester University Press. (Original work published 1979)

McNair, S. (1997). Is there a crisis? Does it matter? In R. Barnett \& A. Griffin (Eds), The end of knowledge in higher education (pp. 27-38). London: Cassell.

Muller, J. (2000). Reclaiming knowledge: Social theory, curriculum and education policy. London: Routledge.

National Commission on Higher Education (NCHE). (1996). A framework for transformation. Pretoria: Author.

Polkinghorne, D.E. (1983). Methodology for the human sciences. Systems of inquiry. Albany: State University of New York.

Polkinghorne, D.E. (1992). Research methodology in humanistic psychology, The Humanistic Psychologist, 20 (1), 218-242.

Richardson, J.T.E. (Ed.) (1996). Handbook of qualitative research methods for psychology and the social sciences. Leicester: British Psychological Society.

Robins, K. \& Webster, F. (1999). Times of the technoculture. From the information society to the virtual life. London: Routledge.

Robson, C. (1993). Real world research: A resource for social scientists and practitioner-researchers. Oxford: Blackwell.

Scott, P. (1995). The meanings of mass higher education. Buckingham: Open University Press.

Scott, P. (1997). The crisis of knowledge and the massification of higher education. In R. Barnett \& A. Griffin (Eds), The end of knowledge in higher education (pp. 14-26). London: Institute of Education.

Slaughter, S. \& Leslie, L.L. (1997). Academic capitalism: Politics, policies, and the entrepreneurial university. Baltimore: Johns Hopkins University Press.

Smith, L. (1984). Ability learning. London: Further Education Unit.

Spady, W.G. (1993). Outcome-based education. Belconnen: Australian Curriculum Studies Association.

Tashakkori, A. \& Teddlie, C. (2003). Issues and dilemmas in teaching research methods courses in social and behavioural sciences: US perspective. International Journal of Social Research Methodology, 6 (1), 61-77.

Tothill, A. \& Crothers, C. (Compiled on behalf of the CSD's research methodology audit team) (1997). Report on social science research methodology teaching at South African tertiary institutions. Pretoria: Human Sciences Research Council.

Wagner, C. (2003). Placing psychology: A critical exploration of research methodology curricula in the social sciences. Unpublished doctoral thesis, University of Pretoria. 